patient took periodically. The presentation and clinical aspect in the form of an acute intravascular haemolytic episode, the small doses of drug sufficient to cause the attacks, the brief time lapse between administration and onset of symptoms, and the positive result of direct Coombs test, with notable components on the erythrocyte surface at the time of the attacks, all indicate that the mechanism responsible is of stibophen or "innocent bystander" type..$^{2-5}$

Nalidixic acid should therefore be added to the list of drugs responsible for immune haemolytic anaemia.

${ }^{1}$ Mandal BK, Stevenson J. Haemolytic crisis produced by nalidixic acid. Lancet 1970;i:614.

${ }^{2}$ Garratty G, Petz LD. Drug-induced immune hemolytic anemia. Am f Med 1975;58:398.

${ }^{3}$ Vila JM, Blum L, Dosik H. Thiazide-induced immune hemolytic anemia. 尹AMA 1976;236:1723.

${ }^{4}$ Wintrobe MM. Clinical hematology. Philadelphia: Lea and Febiger, 1981 : 943-7.

${ }^{5}$ Worlledge SM. Immune drug-induced hemolytic anemia. Semin Hematol 1973;10:327

(Accepted 29 fune 1982)

Unità Operativa di Medicina Generale, Ospedale SM Annunziata USL, IOH 50012 Bagno a Ripoli, Firenze, Italy

ORESTE TAFANI, MD, assistant professor

MARCELLO MAZZOLI, MD, assistant professor

GIANCARLO LANDINI, $M D$, assistant

BRUNO ALTERINI, MD, assistant

\section{Campylobacter colitis associated with erythema nodosum}

When erythema nodosum and mouth ulcers occur in a patient presenting with bloody diarrhoea in whom there is sigmoidoscopic and histological evidence of "colitis" the colitis is usually due to either Crohn's disease or ulcerative colitis. We describe a patient in whom these cutaneous manifestations paralleled the course of campylobacter colitis. Erythema nodosum has not been described previously in association with campylobacter infection. This association may have implications for the pathogenesis of inflammatory bowel disease, infective colitis, and transient colitis syndrome. ${ }^{1}$

\section{Case report}

A 24-year-old woman gave a week's history of frequent watery, bloody diarrhoea associated with colicky lower abdominal pain, which had started six days after she had arrived in Spain. She had also developed tender raised areas on both shins, which she ascribed to insect bites. Ovranette, an oral contraceptive containing ethinyloestradiol and levonorgestrel, was the only medication.

Examination showed a well woman with classical erythema nodosum on both shins. A $0.5 \mathrm{~cm}$ shallow ulcer was present on her lower lip, but there was no eye or genital disease. Direct and rebound tenderness were present in the left iliac fossa. Sigmoidoscopy showed abnormal rectal mucosa with diminished vascularity and contact bleeding. Histology of a rectal biopsy specimen gave appearances of an infective colitis. Campylobacter jejuni was cultured from stool samples, which were negative for Salmonella, Shigella, and Yersinia spp and enteropathogenic Escherichia coli. Clostridium difficile and its toxin were not detected. Virus particles were not detected by direct electron microscopy or culture. A full blood count was normal. A Monospot slide test was negative; yersinia antibodies were absent; and titres of antistreptolysin $\mathrm{O}$, antideoxyribonucleotidase $\mathrm{B}$, antihyaluronidase, and antibodies to cytomegalovirus and Chlamydia psittaci showed no abnormality. A Mantoux test (100 old tuberculin units) was negative. A chest radiograph was normal. Throat swab and blood culture were sterile.

Both the colitis and the cutaneous lesions resolved spontaneously, and she continued taking Ovranette. The erythema nodosum did not reappear, and she remained well three months later.

\section{Comment}

Campylobacter infections have been associated with colitis, and several extraintestinal manifestations including septic and reactive arthritis, cholecystitis, and endocarditis are well recognised. Cutaneous manifestations have not, to our knowledge, been described. A causal relation between the appearance of erythema nodosum, mouth ulcer, and colitis appears to have existed in this patient, and the lesions regressed as the colitis settled. Continuing challenge with Ovranette was not associated with recrudescence, which eliminates this potential cause.

Mouth ulceration and erythema nodosum are both well-recognised cutaneous associations with inflammatory bowel disease. Infective bowel disease has previously been reported only in association with yersinia infections. There was no supportive clinical or pathological evidence for inflammatory bowel disease in our patient. If stool samples had not been sent for microbiological analysis or had been negative for campylobacter (due to previous antibiotic treatment, for example) inflammatory bowel disease such as ulcerative colitis would probably have been diagnosed. She would probably then have received quite inappropriate treatment and become subject to the implications of long-term follow-up.

It has been suggested that there is a form of colitis, possibly of infective aetiology, transient in nature, that may be mistaken for inflammatory bowel disease and that accounted for almost $20 \%$ of one series of patients with acute colitis. ${ }^{1}$ The occurrence of mouth ulcer and erythema nodosum in this patient with campylobacter colitis raises the possibility that a common pathological or immunological mechanism may function in some cases of inflammatory disease and infective colitis.

We thank Dr B C Morson, consultant pathologist, St Mark's Hospital, London, for the histopathology report of the rectal biopsy specimen.

${ }^{1}$ Mandal BK, Schofield PF, Morson BC. A clinico-pathological study of acute colitis: the dilemma of transient colitis syndrome. Scand $\mathcal{f}$ Gastroenterol (in press).

(Accepted 6 fuly 1982)

Regional Department of Infectious Diseases, Monsall Hospital, Manchester M10 8WR

M E ELLIS, MRCP, DCH, senior registrar

J POPE, MB, DOBSTRCOG, senior house officer

A MOKASHI, MD, DCH, registrar

E DUNBAR, MRCP, consultant

\section{Orthogeriatric rehabilitation ward in Nottingham: a preliminary report}

Orthogeriatric wards have been advocated for many years, ${ }^{12}$ and the concept was supported in the Duthie report. ${ }^{3}$ In Nottingham there have been problems with coping with the numbers of orthopaedic patients, and at the peak time of the year in February 1977, 70 orthopaedic patients were "sleeping out" in other departments. The main source of difficulty was the large number of aged patients with trauma, mainly fractured neck of femur. In Nottingham the geriatric service has lacked resources (six beds $/ 1000$ patients over 65 years compared with the Department of Health and Social Security norm of 10 beds/ 1000 patients). In October 1978 an 18-bed orthogeriatric rehabilitation ward was opened in a hospital three miles away from the acute hospital. This orthogeriatric ward was a collaborative project between the orthopaedic and geriatric departments with combined ward rounds and a close working relationship. It was also an attempt to put the available resources of both departments to the most effective use.

We have made a preliminary evaluation of the success of the project by comparing the length of stay for all female patients admitted to the Nottingham hospitals with fractured femur in 1977 (the last complete year before the ward opened) with that in 1979 (the first complete year after the ward opened).

\section{Patients, methods, and results}

Female patients were selected for transfer to the rehabilitation ward 48 hours after operation or as soon as a bed became available. Basically fit patients who were expected to do well without special measures were not sent, nor were those with gross physical or mental defects which would prevent mobilisation. Patients who were expected to respond to a wellstaffed rehabilitation team were selected for the ward; a "triage" system thus operated. Most patients had a fractured neck of femur complicated by other disease or disability, but elderly patients with trauma and any major rehabilitation problem also qualified for the ward. 
Details of the outcome of female patients admitted with fractured neck of femur during 1979 compared with those admitted to the Nottingham hospitals in 1977 are given in the table.

Number of female patients admitted with fractured neck of femur to the orthogeriatric ward in 1979 compared with that for all the Nottingham hospitals in 1977

\begin{tabular}{|c|c|c|c|c|}
\hline & \multicolumn{2}{|c|}{1977} & \multicolumn{2}{|c|}{1979} \\
\hline & No & $\%$ & No & $\%$ \\
\hline $\begin{array}{l}\text { Patients admitted } \\
\text { Discharged }\end{array}$ & 289 & & 482 & \\
\hline $\begin{array}{l}\text { Home } \\
\text { To part III accommodation } \\
\text { To permanent hospital care } \\
\text { Died } \\
\text { Average length of stay (days) }\end{array}$ & $\begin{array}{r}158 \\
28 \\
31 \\
72 \\
66\end{array}$ & $\begin{array}{r}54.5 \\
9.7 \\
10.7 \\
25.0\end{array}$ & $\begin{array}{r}294 \\
44 \\
47 \\
97 \\
48\end{array}$ & $\begin{array}{r}61 \cdot 0 \\
9 \cdot 1 \\
9 \cdot 8 \\
20 \cdot 1\end{array}$ \\
\hline
\end{tabular}

\section{Comment}

Because the average length of stay in hospital fell from 66 to 48 days, a saving of $27 \%$ : beds were thus released for other purposes; 8676 patient/bed/days were saved compared with what would have been notionally used at the 1977 length of stay. Apart from these benefits the orthogeriatric rehabilitation ward has stimulated interest in and enthusiasm for a group of patients who had previously often been thought of as tedious.

We are grateful to Professor Arie for guidance and to Miss J Towers for secretarial help.

${ }^{1}$ Devas MB. Geriatric orthopaedics. London, New York, San Francisco: Academic Press, 1977.

Clark ANG, Wainwright D. The management of the fractured neck of femur in the elderly female. A joint approach of orthopaedic surgery and geriatric medicine. Gerontologia Clinica 1966;8:321-6.

${ }^{3}$ Department of Health and Social Security. Orthopaedic services; waiting time for out-patient appointments and in-patient treatment. London, HMSO : 1981.

(Accepted 8 fuly 1982)

\section{Sherwood Hospital, Nottingham NG5 1PD}

R V BOYD, FRCP, consultant geriatrician, department of health care of the elderly

E COMPTON, FRCS, senior registrar, department of orthopaedics (present appointment: consultant in orthopaedics, Central Nottinghamshire District)

J HAWTHORNE, MB, associate specialist, department of health care of the elderly

J R KEMM, MD, MRCP, lecturer, university department of community medicine

\section{Assessment of Fecatest and Haemoccult for faecal occult blood testing}

In the past few years many data on the usefulness of faecal occult blood testing in screening for colorectal cancer have been collected. We have compared the use of Fecatest (Nordic Ltd) and Haemoccult (Eaton Laboratories) in 1286 individuals. A blood loss of 20-30 ml/ day is required for a positive result to Haemoccult whereas Fecatest has a sensitivity just above what is regarded as normal blood loss $\left(2 \cdot 5-5.0 \mathrm{ml} /\right.$ day). ${ }^{1}$ The kits were used on three successive days after three days of dietary restriction.

\section{Patients, methods, and results}

Three groups of individuals were studied.

Group 1 (factory $A$ )-Factory employees were offered screening for colorectal cancer as part of their annual medical examination. Returned kits (for 757 subjects) were tested in the factory medical department. The age range of the employees tested was $40-65$ years.
Group 2(factory $B$ )-The same screening programme was offered to factory employees by written invitation in their pay packets. Kits (for 405 sub- 으 jects) were posted to the department of gastroenterology, Victoria Hospital, $c$ Blackpool, for interpretation. The age range of the employees tested was $40-\widehat{\Omega}$ 65 years.

Group 3-Outpatients attending the gastroenterology clinic were referred for evaluation of their symptoms. Kits (for 124 patients) were returned personally to the department of gastroenterology. The age range of the $\&$ patients tested was $21-80$ years.

Further investigations-Workers and patients with one or more positive $\varrho$ test result by either method were investigated by flexible sigmoidoscopy, barium enema, and colonoscopy. In group 3 colonoscopy was performed only $\overrightarrow{\vec{F}}$ in patients with negative test results where clinically indicated.

Of 1286 specimens returned for testing, $3.8 \%, 4 \cdot 4 \%$, and $19.6 \%$ gave positive results for Fecatest in groups 1,2 , and 3 respectively and $1.7 \%$, 음 $0.24 \%$, and $9.7 \%$ respectively for Haemoccult. Fecatest was more sensitive $\frac{\bar{S}}{\vec{D}}$ than Haemoccult and produced about twice as many positive results in groups $\mathbb{\mathbb { Q }}$ $1(p<0.05)$ and $3(p<0.01)$ in individuals in whom there was no delay in testing. There was no significant difference in positivity rate for Fecatest between group $1(3.8 \%)$ and group $2(4.4 \%)$, but the Haemoccult positivity $\overrightarrow{0}$ rate was significantly lower in group $2(0.24 \%)$ compared with $1.7 \%(\mathrm{p}<0.05)$, ? probably because of the delay in testing due to transport of the specimens by post.

In 77 individuals with positive test results, carcinoma was diagnosed in six, polyps in five, ulcerating lipoma in one, and inflammatory bowel disease in $\frac{0}{3}$ three and were considered to be the cause of occult bleeding. Also 22 individuals had perianal lesions (haemorrhoids, fissures, excoriations) and seven $\infty$ had diverticular disease; 34 had no perianal or colonic disease.

The positivity rates for clinically serious lesions are shown in the table. of The three carcinomas which were negative to Haemoccult occurred in groups in whom fresh specimens were tested so that postal delay was not responsible for the negative result. In addition to those with positive test $\omega$ results two patients in group 3, who had negative results to Haemoccult and Fecatest, had adenomatous polyps. Though the numbers were small, فे Haemoccult was generally less sensitive for distal colonic lesions than Feca- 을 test.

Results of occult blood testing in cases of clinically serious large bowel disease

\begin{tabular}{lccccc}
\hline Test & Result & Cancer & Polyps* & $\begin{array}{c}\text { Inflammatory } \\
\text { bowel disease }\end{array}$ & $\begin{array}{c}\text { Total No } \\
\text { of cases }\end{array}$ \\
\hline Fecatest & + & 6 & 5 & 3 & 14 \\
Fecatest & - & 0 & 3 & 0 & 3 \\
Haemoccult & + & 3 & 4 & 3 & 10 \\
Haemoccult & - & 3 & 4 & 0 & 7
\end{tabular}

*Including one case of lipoma

$+=$ Positive; $-=$ negative.

\section{Comment}

Two screening programmes in the UK using Haemoccult produced a positivity rate of $3.8 \%$ and $5 \%$ in predominantly elderly populations. ${ }^{2} 3 \mathrm{~A}$ few recent reports have indicated that an undetermined number of colorectal cancers gave negative results to Haemoccult. ${ }^{45}$ With a more sensitive test than Haemoccult, such as Fecatest, an increased positivity rate will be associated with the finding of more serious colorectal pathology and therefore negativity rates will decrease. Some of the false-positive test results may be secondary to upper gastrointestinal pathology, which is not a major problem with Haemoccult. Proper dietary restriction is important and needs to be explained to participants, who have to be strongly motivated to co- 윽 operate. These requirements are more likely to be met in screening a N relatively young population, such as that based on place of work, rather than in surveys based in general practice, which usually include $\frac{D}{O}$ a higher proportion of elderly participants.

1 Adlercreutz H, Liewendahl K, Virkola P. Evaluation of Fecatest, a new Guaiac test for occult blood in faeces. Clin Chen 1978;24:756-61.

${ }^{2}$ Hardcastle JD, Balfour TW, Amar SS. Screening for symptomless colorectal cancer by testing for occult blood in general practice. Lancet 1980; i:791-3.

${ }^{3}$ Farrands PA, Griffiths RL, Britton DC. The Frome experiment-value of screening for colorectal cancer. Lancet 1981 ; : 1231-2.

4 Gnauck R. Occult blood tests. Lancet 1980;i :882.

5 Griffith CDM, Turner DJ, Saunders JH. False-negative results of Haemoccult. $B r$ Med F $1981 ; 283: 472$.

(Accepted 6 fuly 1982)

Department of Gastroenterology, Victoria Hospital, Blackpool, Lancashire

F I LEE, FRCP, consultant

F T COSTELLO, MRCP, registrar 